Suicide Risk and Protective Factors: A Network Approach

Ms M. S. Holman

Dr M. N. Williams

Massey University

This version of the article is an accepted manuscript (post-print), and may not completely replicate the final version of record published in the Archives of Suicide Research at https://doi.org/ 10.1080/13811118.2020.1774454 


\section{Suicide Risk and Protective Factors: A Network Approach}

Objective: Suicide is a complex phenomenon, with numerous factors contributing to an individual's risk of suicide. The aim of the present study was to explore how risk and protective factors for suicide interact with one another in a network sense, and to determine which factors were most central to a network of these factors.

Method: Using an online survey, cross-sectional data was collected from a sample of 515 individuals who lived in New Zealand, Australia, the United Kingdom, and the United States of America. Participants were recruited through either social media or Prolific Academic. A network of 18 risk and protective factors for suicide was estimated using network analysis. Analyses were preregistered on the Open Science Framework.

Results: Factors that had the highest strength centrality were feeling depressed, feeling hopeless, perceived burdensomeness, self-esteem, and social support. Factors that were directly associated with suicidal ideation included feeling depressed, perceived burdensomeness, feeling hopeless, self-esteem, resilience, access to mental health services and a positive attitude towards these services.

Conclusion: This research demonstrates the importance of examining protective factors as well as risk factors when estimating an individual's suicide risk. The results suggest that interventions targeting depression may be particularly beneficial in reducing suicide risk, but further longitudinal research is required.

Keywords: network analysis; protective factors; risk factors; suicide

\section{Highlights}

- The network analyses estimated depression to be the most central risk factor.

- Depression and perceived burdensomeness were risk factors for suicidal ideation

- Self-esteem and resilience were protective against suicidal ideation. 
Suicide is a global concern, with 800,000 deaths estimated to occur worldwide each year (World Health Organization, 2018). Higher rates of occurrence are seen for suicidal ideation, plans, and attempts. Recent statistics for the United States of America estimate that 9.8 million individuals had thoughts of suicide, 2.8 million had a suicide plan, and 1.3 million attempted suicide (National Institute of Mental Health, 2019). For each suicide death in the US population, there were 33 attempted suicides (National Institute of Mental Health, 2019).

Recently, ideation to action theories of suicide, such as the interpersonal psychological theory, integrated motivational-volitional model, and three step theory, have proposed that the factors that lead an individual to experience suicidal ideation differ from the factors that lead them to attempt suicide (for further information, see Joiner, 2005; Klonsky \& May, 2015; O’Connor, 2011). Correspondingly, empirical research has explored which specific risk factors are associated with suicidal ideation, attempts, and death (Franklin et al., 2017). Studying risk factors for suicide can be useful in order to predict which individuals may most need intervention, and to identify factors that may precipitate suicide (and which could be addressed by interventions).

In the literature, risk factors are often described as either static or dynamic. Static risk factors are variables that are historical or relate to demographic information (Sinclair, 2017), such as gender (Schrijvers et al., 2012), ethnicity (Clifford et al., 2013; Pollock et al., 2018), or personal history of self-harm and suicide attempts (Chan et al., 2016; Gibb et al., 2005; Ribeiro et al., 2016). In contrast, dynamic risk factors are those that are situational, changing over time (Sinclair, 2017). As dynamic risk factors can be altered, targeting such variables in suicide prevention methods may be effective in reducing risk, with lower levels of dynamic risk factors generally being associated with 
lower levels of suicidality. Examples of dynamic risk factors for suicide are listed in Table 1.

As well as risk factors for suicide, there also exist protective factors. These are factors that increase an individual's ability to cope and may reduce likelihood of suicide (Chehil \& Kutcher, 2012). Protective factors for suicide have not been researched as prolifically as risk factors have been (de Beurs et al., 2019). Examples of protective factors for suicide are listed in Table 1. Risk and Protective Factors for Suicide Identified in the LiteratureTable 1.

A network analytical approach may help us better understand who is at increased risk of suicide based on the risk and protective factors they experience. Network analysis is a statistical technique that enables researchers to explore complex associations between a group of variables, such as risk factors or symptoms. Emanating from this analysis is a visual network structure, which depicts the associations between variables, as well as the strength and direction of these relationships. Each node in the estimated network represents a variable, for example a risk factor. The connections between nodes are called edges, and these represent associations between nodes. In network analysis, the centrality of each node can be measured. Centrality is a measure of how connected each node is to others in the network (Fonseca-Pedrero, 2018). Nodes with a higher number of connections to other nodes on the network are therefore more central. While there are numerous measures of centrality, the measurement utilized in this study is strength centrality, which sums the strength of all the edges connected to a node (Epskamp, Maris, et al., 2018). Bringmann et al. (2019) review the suitability of centrality indices in psychological networks, and argue that these measures have limitations as indicators of the importance of nodes in psychological networks. This is the case particularly for betweenness and closeness centralities, which will not be reported in this study. 
The use of network analysis in relation to psychopathology was conceptualized by Borsboom (2008). Borsboom suggested that a network perspective provides an alternative explanation for why particular sets of symptoms may seem to "cluster" together. For example, an association between the symptoms low mood and insomnia might be explained not by both being caused by an underlying latent variable of “depression", but rather by a causal effect of one symptom on another (insomnia causing low mood). Numerous network analyses of symptoms of psychopathology have been published since (for example, see Borsboom, 2017; Boschloo et al., 2015; Fried et al., 2016), some of which have explored whether network analysis can be used to guide effective targeted interventions for psychopathology (see Papini et al., 2019; Rodebaugh et al., 2018). Risk factors for suicide may likewise have causal effects on one another; for example, stressful life events may precipitate substance abuse, and perceived burdensomeness may precipitate depression. De Beurs (2017) has argued that estimating a network of factors associated with suicidal behaviour may help researchers to create personalized interventions for suicidal behaviour too.

By using network analysis to investigate the relationships between risk and protective factors for suicide, specific factors may be identified as being central to heightened suicide risk. By changing the state of central risk or protective factors in an individual's suicide risk network, other factors in the network will likely change too. Therefore, if these central factors are targeted in individualized treatment, providing that the interventions are successful, an individual's overall suicide risk may be reduced to a more substantial degree than might otherwise be possible. Though this has yet to be demonstrated in relation to suicide risk, preliminary evidence from studies of psychopathology suggest that targeting central variables in an intervention may be an 
effective way to decrease symptoms network-wide (Papini et al., 2019; Rodebaugh et al., 2018).

\section{Research Aims}

The need to study suicidal behavior in its full complexity has been recognized in the field of suicide prevention. Network analysis has been recognized as a statistical technique that can help us to understand such complexities. In their review of recent developments and challenges for suicide research, O’Connor and Portzky (2018) urged researchers to utilize network analysis when studying suicide. Due to the dearth of network analysis applications to suicide thus far, the present study sought to conduct a network analysis exploring the associations of risk and protective factors for suicide in an international sample to provide further understanding of the complex reciprocal associations such factors have with one another. This is the first cross-sectional network study of suicide risk to utilise an international sample. Furthermore, the risk and protective factors analysed in this study include some not present in previous crosssectional suicide network literature (de Beurs, 2017; de Beurs et al., 2019; Shiratori et al., 2014; Simons et al., 2019). The purpose of this research was to estimate which factors had the strongest direct association with suicidal ideation and which factors were most central to suicide risk.

A novel feature of this study was that a plan for data collection and analysis (including the data analysis script) was preregistered on the Open Science Framework (see Nosek et al., 2018 for an introduction to preregistration). This preregistration can be accessed online at https://osf.io/f395g.

\section{Method}

For a more detailed discussion of the procedure, measures, and analyses, see the 
Supplementary Materials at https://osf.io/b6rk4/.

\section{Participants and Procedure}

Participants recruited for this study resided in New Zealand, Australia, the United States of America, and the United Kingdom. These four countries were recruited from as they are Westernized, largely English speaking, and have similar suicide rates (Australian Bureau of Statistics, 2019; Coronial Services of New Zealand, 2019; National Institute of Mental Health, 2019; Office for National Statistics, 2019). We required a large sample size to achieve stable network estimation (see Sample size subsection), and collecting data from multiple countries facilitated this. Participants were recruited via two methods which operated concurrently. One method involved posting an advertisement to social media, while the other involved advertising the study on Prolific Academic. Prolific Academic facilitates fast data collection, but has relatively few New Zealand members, so the social media method was used to recruit an adequate subsample of New Zealanders (this study was conducted in New Zealand). The preregistration for this study stated that a target sample size of 300 participants would be recruited through Prolific Academic, and 200 through social media. The survey was to remain online either until the survey reached the target of 300 participants from Prolific Academic and 200 participants from social media, or until four weeks had elapsed, whichever occurred first. The "quota" function in Qualtrics was used to count the number of participants who consented to participate, met inclusion criteria for this research (i.e., were aged over 18, and lived in New Zealand, Australia, the United Kingdom, or the United States of America), and had reached the end of the survey, and then stop the survey once the desired sample sizes (300 from Prolific Academic, 200 from social media) were reached. It took two hours to recruit the quota of Prolific Academic participants, and three days to recruit the quota of social media participants. 
Sample size and participant demographics.

There were 534 respondents to the surveys overall (301 from Prolific Academic and 233 from social media). The total number of participants was higher than the target sample size due to a number of participants not reaching the end of the survey, and thus not being counted in the quotas. Of these 534 participants, 532 met the participant inclusion criteria stipulated in the preregistration.

Prior to analyzing the data, an exclusion criterion was applied in line with the preregistration for this research. This stated that participants must have responded to at least $75 \%$ of the Likert items to be included in the analyses. Of the 532 respondents, 17 were excluded from the data analyses for failing to respond to at least 25 of the 33 Likert items $(75 \%)$ in this study. This left a total of 515 participants included in the data analyses. Participant demographic information is summarised in Table 2.

\section{Measures}

Two surveys were created for the purpose of this study using Qualtrics. They both contained items asking about demographic information and the variables of interest to this research. The survey items can be viewed in the Supplementary Materials. One survey was given to all participants recruited through social media, while the other was given to all participants recruited through Prolific Academic. The two surveys had identical items measuring the variables of interest to this study, with small differences in the demographic information collected and the way the survey ended (see Supplementary Materials).

The first section of the survey collected demographic information about the participants, including their gender, age bracket, and the country they live in. The next section of the survey consisted of 33 Likert items relating to the eighteen suicide risk and protective factors. The variables were selected based on evidence from previous 
literature (refer to Table 1) that suggests it is reasonable to assume that these variables are in fact risk and protective factors for suicidal ideation, attempts, and/or suicide death. The response scale for the Likert items measuring these variables ranged from 1 strongly disagree to 5 strongly agree. These items were not taken from pre-existing instruments, in part due to the limited permissions that many instruments of interest had, such that a survey containing items from these instruments could not be published openly. As this research aimed to uphold Open Science practices, enabling transparency and providing other researchers with all of the resources required to replicate this research, including survey items, was a high priority. For this reason, the Likert items used in the survey were created solely for the purpose of this research.

\section{Data Analysis}

The primary aim of this study was to estimate the network of risk and protective factors for suicide using the survey responses of participants. In partial correlation network structures, an edge between two nodes reflects conditional dependence, such that after controlling for all other nodes in the network, the relationship shown between the nodes is not due to the presence of another node in the network (Epskamp, Maris, et al., 2018). The presence of an edge can indicate a potentially causal relationship between two nodes (Epskamp, Maris, et al., 2018).

Using R version 3.6.0 (R Core Team, 2019) the bootnet package (Epskamp, Borsboom, et al., 2018) was used to estimate the network structure of associations between the eighteen risk and protective factors measured in this research. The network was regularised using the least absolute shrinkage and selection operator (LASSO) method with Extended Bayesian Information Criterion (EBIC) model selection to select the best network, as per the preregistration. The qgraph package (Epskamp et al., 2012) was used to calculate the strength centrality for each node. Though measures of 
centrality have limitations in psychological networks (Bringmann et al., 2019), strength centrality remains a useful heuristic for identifying which nodes might play an important role in the network. Although our preregistration did not explicate which measure of centrality we would report, we report strength centrality, given that Bringmann et al. (2019) indicate that betweenness and closeness centrality measures are particularly ill-suited to psychological networks.

\section{Stability analyses}

Several analyses were conducted to check network accuracy and stability, using the bootnet package, as per the preregistration for this study. Analyzing the stability of networks may help to avoid drawing false conclusions from the network structure about the importance of some variables as well as their relationships. The stability analyses included testing for edge-weight accuracy, centrality stability, edge-weight difference, and centrality difference, as described in a tutorial paper by Epskamp, Borsboom, et al. (2018). The results of these stability tests are included in the Supplementary Materials.

\section{Gender analyses}

A secondary aim of this research was to analyse the differences between the network structures of males and females. The preregistered gender analyses and results of these are discussed in the Supplementary Materials.

\section{Data Sharing Policy}

An anonymised copy of the data used for this research has been made available on the Open Science Framework, along with the R script that was used to run the analyses. These materials can be accessed at https://osf.io/f395g. 


\section{Ethics}

Approval for this study was given by the University X Human Ethics Committee. All participants were provided with phone numbers for relevant suicide prevention help lines.

\section{Results}

Descriptive statistics for the nodes in the network are included in Table 3. A discussion of the descriptive statistics is included in the Supplementary Materials..

\section{Network Estimation}

The network structure of risk and protective factors for suicide is presented in Figure 1. As this is a regularised partial correlation network, the associations that are visible in Figure 1 are only those which remain after controlling for all the other nodes in the network and removing statistically spurious associations. Consequently, even very small associations shown in this network estimation may be meaningful, as there is evidence that these associations were not equal to zero.

The nodes stable employment and financial stability showed the strongest positive association (partial correlation (hereafter $r_{p}$ ) $=.48$ ) in the network, followed by the nodes problem solving and resilience $\left(r_{p}=.40\right)$. Moderate positive associations were seen between the nodes feeling depressed and feeling hopeless $\left(r_{p}=.38\right)$, feeling hopeless and perceived burdensomeness $\left(r_{p}=.38\right)$, feeling depressed and suicidal ideation $\left(r_{p}=.33\right)$, and feeling anxious and feeling depressed $\left(r_{p}=.33\right)$. Slightly weaker positive associations were seen between access to mental health services and the nodes social support $\left(r_{p}=.29\right)$ and positive attitude towards mental health services $\left(r_{p}=.29\right)$. 
There were a large number of very weak positive associations between nodes in the estimated network. Such associations were seen between the node perceived burdensomeness and the nodes feeling anxious $\left(r_{p}=.12\right)$ and suicidal ideation $\left(r_{p}=.12\right)$, and between feeling hopeless and suicidal ideation $\left(r_{p}=.10\right)$. The network structure also showed that self-esteem had weak negative associations with feeling depressed $\left(r_{p}=-\right.$ $.23)$ and perceived burdensomeness $\left(r_{p}=-.19\right)$.

The strength centrality of nodes in the estimated network of risk and protective factors for suicide is shown in Figure 2. The node with the highest strength centrality was feeling depressed, followed by feeling hopeless. The nodes self-esteem, perceived burdensomeness, and social support were also central to the estimated network, showing moderate strength centrality. The least central nodes in terms of strength centrality were being bullied and substance abuse.

\section{Discussion}

The present study has detailed a novel approach to understanding the risk and protective factors for suicide. The preregistered aim of the present study was to find out which factors were most central in a network of suicide risk and protective factors.

The risk factors in the estimated network that had the highest strength centrality were feeling depressed, feeling hopeless, and perceived burdensomeness. These factors had the first, second, and fourth highest strength centrality respectively. Feeling depressed was the most central variable, which was similarly the case in Shiratori et al.’s (2014) estimated network of reasons why people suicided. Depression, hopelessness, and perceived burdensomeness are consistently associated with suicide in the empirical literature (for example Hallensleben et al., 2019), so it is unsurprising that these variables are three of the most central risk factors to suicide risk in the present study. Additionally, feeling hopeless and perceived burdensomeness are implicated in 
modern theories of suicide, including the interpersonal psychological theory (Joiner, 2005), integrated motivational-volitional model (O'Connor, 2011), and three step theory (Klonsky \& May, 2015).

The protective factors with the highest strength centrality in the estimated network were self-esteem and social support, having the third and fifth highest strength centrality respectively. Finding these two protective factors to have high strength centrality in the estimated network suggests that these may be important factors to consider when determining suicide risk. Instead of exclusively focusing on the reduction of risk, taking an approach to suicide prevention that is also strengths-based and focuses on developing protection against suicidal behaviour could potentially be an effective strategy to reduce risk. By acting to enhance the protective factors that are highly central (in tandem with reducing those factors which put someone at increased suicide risk), it may be possible to reduce suicide risk.

As well as examining the centrality of nodes, the present study aimed to determine which nodes were directly associated with suicidal ideation. In the estimated network, the factors that were most strongly associated with suicidal ideation were feeling depressed, perceived burdensomeness, and feeling hopeless, followed by access to mental health services, a positive attitude towards mental health services, self-esteem, and resilience. The association between suicidal ideation and depression was the strongest of these relationships, with a moderate positive correlation estimated between these variables. In previous suicide network research, Simons et al. (2019) and De Beurs et al. (2019) reported a positive association between suicidal ideation and depression or depressive symptoms. Additionally, De Beurs et al. (2019) reported an association between suicidal ideation and both perceived burdensomeness and resilience, which the results of the present study support. Furthermore, a number of non- 
network studies report similar findings to the present study, with negative relationships between suicidality and self-esteem (Fergusson et al., 2003; Thompson \& Light, 2011), access to mental health services (Reynders et al., 2015; Stanley et al., 2016), and positive attitude towards mental health services (Stanley et al., 2016).

A number of protective factors were directly negatively related to suicidal ideation, with higher levels of these variables being associated with less suicidal ideation. These protective factors were resilience, self-esteem, access to mental health services, and a positive attitude towards mental health services.

\section{Limitations and Future Research Recommendations}

\section{Sample}

It is not known whether the convenience sample used is representative of the populations sampled from, especially in regard to characteristics like ethnicity, which was not measured. Because of this, it is unknown whether ethnic groups that are at disproportionately high risk for suicide have been represented in this study, and therefore the results should not be assumed to generalise to such populations. Other demographic characteristics that were not representative of the populations sampled from include gender and country. The sample included twice as many females as males, and there were also comparatively fewer participants from Australia than there were from New Zealand, the United States of America, and the United Kingdom. Furthermore, only these four countries were sampled from, and thus the results of this study cannot generalise beyond these.

\section{Sample size}

To conduct a stable network analysis, there needs to be at least as many observations as 
there are parameters (de Beurs, 2017). With eighteen risk and protective factors included in the analyses, this meant that there were 171 possible parameters $(18 \times 17 / 2$ $=153$ pairwise association parameters, plus 18 threshold parameters $=171$ ), and therefore at least 171 participants were needed to ensure the network analyses were stable. This target was met or surpassed for each estimated network, with 515 participants included in the main network analysis, 338 in the female network analysis, and 171 in the male network analysis. However, we acknowledge this was a relatively small sample in the context of network research, with some such studies analyzing the data of thousands of participants. Ideally, future suicide network research should aim to recruit a sample that is very much in excess of the minimum number required. This may increase the power of the analyses, potentially increasing the stability of the network estimation, and reliability of edge-weight estimations.

\section{Cross-sectional data}

The use of cross-sectional data in network analyses, like that of the present study, results in the direction of any causal relationships between nodes being undeterminable. In order to describe the directionality of the relationships, time series data should be collected, with participants filling in measurements at multiple instances across a period of time (e.g., Rath et al., 2019; see also Borsboom \& Cramer, 2013). Epskamp, van Borkulo, et al. (2018) describe this temporal prediction as possibly being indicative of causality, in that the cause is an antecedent to the effect. To further test hypotheses about causal relationships, experimental research that manipulates nodes should also be conducted. Knowledge gleaned from experiments testing the relationship between two nodes when one is experimentally manipulated would provide evidence for or against the causality of associations present in network analyses, which at this stage are only presumed to be causal. 


\section{Network Regularization}

LASSO was used to regularize the estimated network. A limitation of this type of regularization is that it assumes that the true network is sparse (Epskamp, Borsboom, et al., 2018). Recently Bayesian estimation has been suggested as an alternative method to regularization (Williams \& Mulder, 2019). Using our open data, researchers may wish to estimate the network using alternative regularization methods such as this.

\section{Practical Implications}

Within our network analysis, individual-level dynamic characteristics and psychopathology such as depression and perceived burdensomeness were the most central suicide risk factors while variables such as stable employment and financial stability were less central. This suggests providing treatment which targets these individual-level factors may be a more useful way to reduce suicide risk. Though addressing well-being at a population level has intrinsic value, reducing suicide rates is still likely to require interventions that are specifically focused on enhancing the psychological functioning of individuals, particularly for individuals who are at high risk of suicide. The results of the present study suggest that addressing depression may be a particularly effective method of suicide prevention. Feeling depressed had the highest strength centrality in the estimated network and also had a direct positive association with suicidal ideation.

Depression is dynamic (Nelson et al., 2017), suggesting that a person's level of depression is changeable, such that it could be altered through psychological treatment. At present, there are a number of well-established psychological (Linde et al., 2015) and pharmaceutical (Cipriani et al., 2018) treatments for depression. Despite individuals preferring psychological treatment for depression significantly more than pharmacological treatment (McHugh et al., 2013), many people with depression do not 
receive psychological treatment. By increasing access to adequate psychological treatment, individuals with depression could experience a decrease in symptoms of depression, and thus potentially a decrease in suicide risk too. Studies exploring treatment for depression as a method of reducing suicidal ideation have thus far shown promising results. In a study by Mewton and Andrews (2015), internet-delivered cognitive-behavioural therapy for depression significantly decreased the level of both depression and suicidal ideation, with moderate to large effect sizes. Though this is a seemingly obvious suggestion for how to reduce depression and suicide risk, the results of the present study suggest that increasing accessibility to efficacious treatment for depression might indeed be one of the most effective ways to prevent suicides.

The ability to prevent suicide through psychological treatment hinges on an individual being in a position to receive help from a mental health service, and research suggests this does not happen at a high rate among people experiencing suicidal ideation (Reynders et al., 2015; Stanley et al., 2016). Individuals who are having suicidal thoughts may choose not to seek help from mental health services in part due to a variety of structural and attitudinal barriers to treatment, including financial difficulty, availability of service, perceived ineffectiveness of treatment, and believing their problem to be insignificant (Bruffaerts et al., 2011). Therefore, in order to increase helpseeking behaviour, and in turn be able to address an individual's internal suicide risk factors in psychological treatment, it may help to address (actual and perceived) barriers to mental health services (Holman \& Williams, 2019).

\section{Conclusion}

In an attempt to increase our understanding of how risk and protective factors interact with one another, the present study applied network analysis to common risk and protective factors for suicide. Feeling depressed, feeling hopeless, and perceived 
burdensomeness were central risk factors for suicide, while self-esteem and social support were central protective factors. Many risk factors were directly associated with suicidal ideation, including feeling depressed, perceived burdensomeness, substance abuse, feeling hopeless, and feeling anxious. Additionally, four protective factors had direct negative connections to suicidal ideation: resilience, self-esteem, access to mental health services, and positive attitude towards these services. The network approach to examining suicide risk and protective factors has thus far shown itself to be enlightening. With further research and the eventual development of targeted interventions for suicide, there is reason to hope that a reduction in suicide rates may occur in the future.

\section{Disclosure Statement}

No potential conflict of interest was reported by the authors.

\section{Data Availability Statement}

The data that support the findings of this study are openly available on the Open Science Framework at https://osf.io/f395g 


\section{References}

Abdollahi, A., Talib, M. A., Yaacob, S. N., \& Ismail, Z. (2015). Problem-solving skills appraisal mediates hardiness and suicidal ideation among Malaysian undergraduate students. PLOS ONE, 10(4), e0122222. https://doi.org/10.1371/journal.pone.0122222

Australian Bureau of Statistics. (2019). Australia suicide data 2018. https://s3-apsoutheast2.amazonaws.com/lifeinmind/assets/src/uploads/National_slides_2018.pdf

Beautrais, A. L. (2003). Suicide in New Zealand II: A review of risk factors and prevention. New Zealand Medical Journal, 116(1175). https://www.ncbi.nlm.nih.gov/pubmed/12838357

Beautrais, A. L., Joyce, P. R., \& Mulder, R. T. (1997). Precipitating factors and life events in serious suicide attempts among youths aged 13 through 24 years. Journal of the American Academy of Child and Adolescent Psychiatry, 36(11), 1543-1551. https://doi.org/10.1016/S0890-8567(09)66563-1

Beck, A. T., Steer, R. A., Kovacs, M., \& Garrison, B. (1985). Hopelessness and eventual suicide: A 10-year prospective study of patients hospitalized with suicidal ideation. American Journal of Psychiatry, 142(5), 559-563. https://doi.org/10.1176/ajp.142.5.559

Bell, C. M., Ridley, J. A., Overholser, J. C., Young, K., Athey, A., Lehmann, J., \& Phillips, K. (2018). The role of perceived burden and social support in suicide and depression. Suicide and Life-Threatening Behavior, 48(1), 87-94. https://doi.org/10.1111/sltb.12327

Borsboom, D. (2008). Psychometric perspectives on diagnostic systems. Journal of Clinical Psychology, 64(9), 1089-1108. https://doi.org/10.1002/jclp.20503 
Borsboom, D. (2017). A network theory of mental disorders. World Psychiatry, 16(1), 5-13. https://doi.org/10.1002/wps.20375

Borsboom, D., \& Cramer, A. O. J. (2013). Network analysis: An integrative approach to the structure of psychopathology. Annual Review of Clinical Psychology, 9(1), 91-121. https://doi.org/10.1146/annurev-clinpsy-050212-185608

Boschloo, L., van Borkulo, C. D., Rhemtulla, M., Keyes, K. M., Borsboom, D., \& Schoevers, R. A. (2015). The network structure of symptoms of the Diagnostic and Statistical Manual of Mental Disorders. PLOS ONE, 10(9), e0137621. https://doi.org/10.1371/journal.pone.0137621

Brådvik, L., Mattisson, C., Bogren, M., \& Nettelbladt, P. (2008). Long-term suicide risk of depression in the Lundby cohort 1947-1997—Severity and gender. Acta Psychiatrica Scandinavica, 117(3), 185-191. https://doi.org/10.1111/j.16000447.2007.01136.x

Bringmann, L., Elmer, T., Epskamp, S., Krause, R., Schoch, D., Wichers, M., Wigman, J., \& Snippe, E. (2019). What do centrality measures measure in psychological networks? Journal of Abnormal Psychology, 128(8), 892-903. https://doi.org/10.1037/abn0000446

Bruffaerts, R., Demyttenaere, K., Hwang, I., Chiu, W.-T., Sampson, N., Kessler, R. C., Alonso, J., Borges, G., de Girolamo, G., de Graaf, R., Florescu, S., Gureje, O., Hu, C., Karam, E. G., Kawakami, N., Kostyuchenko, S., Kovess-Masfety, V., Lee, S., Levinson, D., ... Nock, M. K. (2011). Treatment of suicidal people around the world. British Journal of Psychiatry, 199(1), 64-70. https://doi.org/10.1192/bjp.bp.110.084129

Chan, M. K. Y., Bhatti, H., Meader, N., Stockton, S., Evans, J., O’Connor, R. C., Kapur, N., \& Kendall, T. (2016). Predicting suicide following self-harm: A 
systematic review of risk factors and risk scales. British Journal of Psychiatry, 209(4), 277. https://doi.org/10.1192/bjp.bp.115.170050

Chehil, Sonia., \& Kutcher, S. P. (2012). Suicide risk management: A manual for health professionals (2nd ed.). John Wiley \& Sons, Ltd. https://www.wiley.com/enus/Suicide+Risk+Management\%3A+A+Manual+for+Health+Professionals\%2C +2nd+Edition-p-9780470978566

Cherpitel, C. J., Borges, G. L. G., \& Wilcox, H. C. (2004). Acute alcohol use and suicidal behavior: A review of the literature. Alcoholism: Clinical and Experimental Research, 28(5), S18-S28. https://doi.org/10.1097/01.ALC.0000127411.61634.14

Chesney, E., Goodwin, G. M., \& Fazel, S. (2014). Risks of all-cause and suicide mortality in mental disorders: A meta-review. World Psychiatry, 13(2), 153160. https://doi.org/10.1002/wps.20128

Cipriani, A., Furukawa, T. A., Salanti, G., Chaimani, A., Atkinson, L. Z., Ogawa, Y., Leucht, S., Ruhe, H. G., Turner, E. H., Higgins, J. P. T., Egger, M., Takeshima, N., Hayasaka, Y., Imai, H., Shinohara, K., Tajika, A., Ioannidis, J. P. A., \& Geddes, J. R. (2018). Comparative efficacy and acceptability of 21 antidepressant drugs for the acute treatment of adults with major depressive disorder: A systematic review and network meta-analysis. FOCUS, 16(4), 420429. https://doi.org/10.1176/appi.focus. 16407

Clifford, A. C., Doran, C. M., \& Tsey, K. (2013). A systematic review of suicide prevention interventions targeting indigenous peoples in Australia, United States, Canada and New Zealand. BMC Public Health, 13(1), 1-11. https://doi.org/10.1186/1471-2458-13-463 
Conner, K. R., Huguet, N., Caetano, R., Giesbrecht, N., McFarland, B. H., Nolte, K. B., \& Kaplan, M. S. (2013). Acute use of alcohol and methods of suicide in a US national sample. American Journal of Public Health, 104(1), 171-178. https://doi.org/10.2105/AJPH.2013.301352

Connor, K. R. (2011). A call for research on planned vs unplanned suicidal behavior. Suicide and Life-Threatening Behavior, 34(2), 89-98. https://doi.org/10.1521/suli.34.2.89.32780

Coope, C., Donovan, J., Wilson, C., Barnes, M., Metcalfe, C., Hollingworth, W., Kapur, N., Hawton, K., \& Gunnell, D. (2015). Characteristics of people dying by suicide after job loss, financial difficulties and other economic stressors during a period of recession (2010-2011): A review of coroners' records. Journal of Affective Disorders, 183, 98-105. https://doi.org/10.1016/j.jad.2015.04.045

Coronial Services of New Zealand. (2019). Provisional figures-August 2019. https://coronialservices.justice.govt.nz/assets/Documents/Publications/Provision al-Figures-August-2019.pdf

de Beurs, D. (2017). Network analysis: A novel approach to understand suicidal behaviour. International Journal of Environmental Research and Public Health, 14(3), 219. https://doi.org/10.3390/ijerph14030219

de Beurs, D., Fried, E., Wetherall, K., Cleare, S., O’Connor, D., Ferguson, E., O’Carroll, R., \& O’Connor, R. (2019). Exploring the psychology of suicidal ideation: A theory driven network analysis. Behaviour Research and Therapy, 120. https://doi.org/10.1016/j.brat.2019.103419

De Hert, M., McKenzie, K., \& Peuskens, J. (2001). Risk factors for suicide in young people suffering from schizophrenia: A long-term follow-up study. 
Schizophrenia Research, 47(2), 127-134. https://doi.org/10.1016/S09209964(00)00003-7

Epskamp, S., Borsboom, D., \& Fried, E. I. (2018). Estimating psychological networks and their accuracy: A tutorial paper. Behavior Research Methods, 50(1), 195212. https://doi.org/10.3758/s13428-017-0862-1

Epskamp, S., Cramer, A. O. J., Waldorp, L. J., Schmittmann, V. D., \& Borsboom, D. (2012). qgraph: Network visualizations of relationships in psychometric data. Journal of Statistical Software, 48(4), 1-18.

Epskamp, S., Maris, G. K. J., Waldorp, L. J., \& Borsboom, D. (2018). Network Psychometrics. In P. Irwing, T. Booth, \& D. J. Hughes (Eds.), The Wiley Handbook of Psychometric Testing: A Multidisciplinary Reference on Survey, Scale and Test Development.

Epskamp, S., van Borkulo, C., van der Veen, D. C., Servaas, M. N., Isvoranu, A.-M., Riese, H., \& Cramer, A. O. J. (2018). Personalized network modeling in psychopathology: The importance of contemporaneous and temporal connections. Clinical Psychological Science, 6, 416-427. https://doi.org/10.1177/2167702617744325

Fergusson, D. M., Beautrais, A. L., \& Horwood, L. J. (2003). Vulnerability and resiliency to suicidal behaviours in young people. Psychological Medicine, 33(1), 61-73. https://doi.org/10.1017/S0033291702006748

Flensborg-Madsen, T., Knop, J., Mortensen, E. L., Becker, U., Sher, L., \& Gronbaek, M. (2009). Alcohol use disorders increase the risk of completed suicideIrrespective of other psychiatric disorders. A longitudinal cohort study. Psychiatry Research, 167(1), 123-130. https://doi.org/10.1016/j.psychres.2008.01.008 
Fonseca-Pedrero, E. (2018). Network analysis in psychology. Papeles Del Psicólogo Psychologist Papers, 39(1), 1-12. https://doi.org/10.23923/pap.psicol2018.2852

Foster, T. (2011). Adverse life events proximal to adults suicide: A synthesis of findings from psychological autopsy studies. Archives of Suicide Research, 15(1), 1-15. https://doi.org/10.1080/13811118.2011.540213

Franklin, J. C., Ribeiro, J. D., Fox, K. R., Bentley, K. H., Kleiman, E. M., Huang, X., Musacchio, K. M., Jaroszewski, A. C., Chang, B. P., \& Nock, M. K. (2017). Risk factors for suicidal thoughts and behaviors: A meta-analysis of 50 years of research. Psychological Bulletin, 143(2), 187-232. https://doi.org/10.1037/bul0000084

Fried, E. I., Epskamp, S., Nesse, R. M., Tuerlinckx, F., \& Borsboom, D. (2016). What are 'good' depression symptoms? Comparing the centrality of DSM and nonDSM symptoms of depression in a network analysis. Journal of Affective Disorders, 189, 314-320. https://doi.org/10.1016/j.jad.2015.09.005

Gibb, S. J., Beautrais, A. L., \& Fergusson, D. M. (2005). Mortality and further suicidal behaviour after an index suicide attempt: A 10 year study. Australian and New Zealand Journal of Psychiatry, 39(1), 95-100. https://doi.org/10.1080/j.14401614.2005.01514.x

Hallensleben, N., Glaesmer, H., Forkmann, T., Rath, D., Strauss, M., Kersting, A., \& Spangenberg, L. (2019). Predicting suicidal ideation by interpersonal variables, hopelessness and depression in real-time. An ecological momentary assessment study in psychiatric inpatients with depression. European Psychiatry, 56, 43-50. https://doi.org/10.1016/j.eurpsy.2018.11.003 
Hatcher, S., \& Stubbersfield, O. (2013). Sense of belonging and suicide: A systematic review. The Canadian Journal of Psychiatry, 58(7), 432-436. https://doi.org/10.1177/070674371305800709

Hinduja, S., \& Patchin, J. W. (2010). Bullying, cyberbullying, and suicide. Archives of Suicide Research, 14(3), 206-211. https://doi.org/10.1080/13811118.2010.494133

Holman, M., \& Williams, M. (2019). Young New Zealanders' Beliefs About Youth Suicide and How It Can Be Prevented [Preprint]. PsyArXiv. https://psyarxiv.com/wgmp4/

Holt, M. K., Vivolo-Kantor, A. M., Polanin, J. R., Holland, K. M., DeGue, S., Matjasko, J. L., Wolfe, M., \& Reid, G. (2015). Bullying and suicidal ideation and behaviors: A meta-analysis. Pediatrics, 135(2). https://doi.org/10.1542/peds.2014-1864

Joiner, T. E. (2005). Why people die by suicide. Harvard University Press.

Joiner, T. E., Pettit, J. W., Walker, R. L., Voelz, Z. R., Cruz, J., Rudd, M. D., \& Lester, D. (2002). Perceived burdensomeness and suicidality: Two studies on the suicide notes of those attempting and those completing suicide. Journal of Social and Clinical Psychology, 21(5), 531-545. https://doi.org/10.1521/jscp.21.5.531.22624

Kanwar, A., Malik, S., Prokop, L. J., Sim, L. A., Feldstein, D., Wang, Z., \& Murad, M. H. (2013). The association between anxiety disorders and suicidal behaviors: A systematic review and meta-analysis. Depression and Anxiety, 30(10), 917-929. https://doi.org/10.1002/da.22074 
Kleiman, E. M., \& Liu, R. T. (2013). Social support as a protective factor in suicide: Findings from two nationally representative samples. Journal of Affective Disorders, 150(2), 540-545. https://doi.org/10.1016/j.jad.2013.01.033

Kleiman, E. M., Riskind, J. H., Schaefer, K. E., \& Weingarden, H. (2012). The moderating role of social support on the relationship between impulsivity and suicide risk. Crisis: The Journal of Crisis Intervention and Suicide Prevention, 33(5), 273-279. https://doi.org/10.1027/0227-5910/a000136

Klonsky, E. D., \& May, A. M. (2015). The three-step theory (3ST): A new theory of suicide rooted in the 'ideation-to-action' framework. International Journal of Cognitive Therapy, 8(2), 114-129. https://doi.org/10.1521/ijct.2015.8.2.114

Kuo, W. H., Gallo, J. J., \& Eaton, W. W. (2004). Hopelessness, depression, substance disorder, and suicidality-A 13-year community-based study. Social Psychiatry and Psychiatric Epidemiology, 39(6), 497-501. https://doi.org/10.1007/s00127004-0775-Z

Linda, W. P., Marroquín, B., \& Miranda, R. (2012). Active and passive problem solving as moderators of the relation between negative life event stress and suicidal ideation among suicide attempters and non-attempters. Archives of Suicide Research: Official Journal of the International Academy for Suicide Research, 16(3), 183-197. https://doi.org/10.1080/13811118.2012.695233

Linde, K., Sigterman, K., Kriston, L., Rucker, G., Jamil, S., Meissner, K., \& Schneider, A. (2015). Effectiveness of psychological treatments for depressive disorders in primary care: Systematic review and meta-analysis. The Annals of Family Medicine, 13(1), 56-68. https://doi.org/10.1370/afm.1719 
May, A. M., \& Klonsky, E. D. (2015). 'Impulsive' suicide attempts: What do we really mean? Personality Disorders: Theory, Research, and Treatment, 7(3), 293-302. https://doi.org/10.1037/per0000160

McHugh, R. K., Whitton, S. W., Peckham, A. D., Welge, J. A., \& Otto, M. W. (2013). Patient preference for psychological vs. pharmacological treatment of psychiatric disorders: A meta-analytic review. The Journal of Clinical Psychiatry, 74(6), 595-602. https://doi.org/10.4088/JCP.12r07757

Mewton, L., \& Andrews, G. (2015). Cognitive behaviour therapy via the internet for depression: A useful strategy to reduce suicidal ideation. Journal of Affective Disorders, 170, 78-84. https://doi.org/10.1016/j.jad.2014.08.038

Min, K.-B., Park, S.-G., Hwang, S. H., \& Min, J.-Y. (2015). Precarious employment and the risk of suicidal ideation and suicide attempts. Preventive Medicine, 71, 72-76. https://doi.org/10.1016/j.ypmed.2014.12.017

National Institute of Mental Health. (2019). Suicide. https://www.nimh.nih.gov/health/statistics/suicide.shtml

Nelson, B., McGorry, P. D., Wichers, M., Wigman, J. T. W., \& Hartmann, J. A. (2017). Moving from static to dynamic models of the onset of mental disorder: A review. JAMA Psychiatry, 74(5), 528. https://doi.org/10.1001/jamapsychiatry.2017.0001

Nosek, B. A., Ebersole, C. R., DeHaven, A. C., \& Mellor, D. T. (2018). The preregistration revolution. Proceedings of the National Academy of Sciences, 115(11), 2600-2606. https://doi.org/10.1073/pnas.1708274114

O'Connor, R. C. (2011). Towards an integrated motivational-volitional model of suicidal behaviour. In International Handbook of Suicide Prevention (pp. 181198). John Wiley \& Sons, Ltd. https://doi.org/10.1002/9781119998556.ch11 
O’Connor, R. C., \& Portzky, G. (2018). Looking to the future: A synthesis of new developments and challenges in suicide research and prevention. Frontiers in Psychology, 9. https://doi.org/10.3389/fpsyg.2018.02139

Office for National Statistics. (2019). Suicides in the UK.

https://www.ons.gov.uk/peoplepopulationandcommunity/birthsdeathsandmarria ges/deaths/bulletins/suicidesintheunitedkingdom/2018registrations

Papini, S., Rubin, M., Telch, M. J., Smits, J. A. J., \& Hien, D. A. (2019). Pre-treatment post-traumatic stress disorder symptom network metrics predict the strength of the association between node change and network change during treatment. Journal of Traumatic Stress, O(0). https://doi.org/10.1002/jts.22379

Pollock, N. J., Naicker, K., Loro, A., Mulay, S., \& Colman, I. (2018). Global incidence of suicide among Indigenous peoples: A systematic review. BMC Medicine, 16(1), 1-17. https://doi.org/10.1186/s12916-018-1115-6

Poorolajal, J., Haghtalab, T., Farhadi, M., \& Darvishi, N. (2016). Substance use disorder and risk of suicidal ideation, suicide attempt and suicide death: A metaanalysis. Journal of Public Health, 38(3), e282-e291. https://doi.org/10.1093/pubmed/fdv148

Qiu, T., Klonsky, E. D., \& Klein, D. N. (2017). Hopelessness predicts suicide ideation but not attempts: A 10-year longitudinal study. Suicide and Life-Threatening Behavior, 47(6), 718-722. https://doi.org/10.1111/sltb.12328

Quiñones, V., Jurska, J., Fener, E., \& Miranda, R. (2015). Active and passive problem solving: Moderating role in the relation between depressive symptoms and future suicidal ideation varies by suicide attempt history. Journal of Clinical Psychology, 71(4), 402-412. https://doi.org/10.1002/jclp.22155 
R Core Team. (2019). R: A language and environment for statistical computing. $\mathrm{R}$ Foundation for Statistical Computing. https://www.R-project.org/

Rath, D., de Beurs, D., Hallensleben, N., Spangenberg, L., Glaesmer, H., \& Forkmann, T. (2019). Modelling suicide ideation from beep to beep: Application of network analysis to ecological momentary assessment data. Internet Interventions, 18. https://doi.org/10.1016/j.invent.2019.100292

Reynders, A., Kerkhof, A. J. F. M., Molenberghs, G., \& Van Audenhove, C. (2015). Help-seeking, stigma and attitudes of people with and without a suicidal past. A comparison between a low and a high suicide rate country. Journal of Affective Disorders, 178, 5-11. https://doi.org/10.1016/j.jad.2015.02.013

Ribeiro, J. D., Franklin, J. C., Fox, K. R., Bentley, K. H., Kleiman, E. M., Chang, B. P., \& Nock, M. K. (2016). Self-injurious thoughts and behaviours as risk factors for suicide ideation, attempts, and death: A meta-analysis of longitudinal studies. Psychological Medicine, 46, 225-236. https://doi.org/10.1017/S0033291715001804

Rodebaugh, T. L., Tonge, N. A., Piccirillo, M. L., Fried, E., Horenstein, A., Morrison, A. S., Goldin, P., Gross, J. J., Lim, M. H., Fernandez, K. C., Blanco, C., Schneier, F. R., Bogdan, R., Thompson, R. J., \& Heimberg, R. G. (2018). Does centrality in a cross-sectional network suggest intervention targets for social anxiety disorder? Journal of Consulting and Clinical Psychology, 86(10), 831844. https://doi.org/10.1037/ccp0000336

Roeger, L., Allison, S., Korossy-Horwood, R., Eckert, K. A., \& Goldney, R. D. (2010). Is a history of school bullying victimization associated with adult suicidal ideation? A South Australian population-based observational study. Journal of 
Nervous and Mental Disease, 198(10), 728-733.

https://doi.org/10.1097/NMD.0b013e3181f4aece

Roy, A., Sarchiapone, M., \& Carli, V. (2007). Low resilience in suicide attempters. Archives of Suicide Research, 11(3), 265-269. https://doi.org/10.1080/13811110701403916

Schrijvers, D. L., Bollen, J., \& Sabbe, B. G. C. (2012). The gender paradox in suicidal behavior and its impact on the suicidal process. Journal of Affective Disorders, 138(1-2), 19-26. https://doi.org/10.1016/j.jad.2011.03.050

Sher, L. (2019). Resilience as a focus of suicide research and prevention. Acta Psychiatrica Scandinavica, acps.13059. https://doi.org/10.1111/acps.13059

Shiratori, Y., Tachikawa, H., Nemoto, K., Endo, G., Aiba, M., Matsui, Y., \& Asada, T. (2014). Network analysis for motives in suicide cases: A cross-sectional study. Psychiatry and Clinical Neurosciences, 68(4), 299-307. https://doi.org/10.1111/pcn.12132

Simons, J. S., Simons, R. M., Walters, K. J., Keith, J. A., O’Brien, C., Andal, K., \& Stoltenberg, S. F. (2019). Nexus of despair: A network analysis of suicidal ideation among veterans. Archives of Suicide Research, 1-23. https://doi.org/10.1080/13811118.2019.1574689

Sinclair, L. (2017). Exploring thoughts of suicide. British Medical Journal, 356. https://doi.org/10.1136/bmj.j1128

Stanley, I. H., Hom, M. A., \& Joiner, T. E. (2016). A systematic review of suicidal thoughts and behaviors among police officers, firefighters, EMTs, and paramedics. Clinical Psychology Review, 44, 25-44. https://doi.org/10.1016/j.cpr.2015.12.002 
Teismann, T., Paashaus, L., Siegmann, P., Nyhuis, P., Wolter, M., \& Willutzki, U. (2019). Suicide attempters, suicide ideators, and non-ideators: Differences in protective factors. Crisis: The Journal of Crisis Intervention and Suicide Prevention, 40(4), 294-297. https://doi.org/10.1027/0227-5910/a000554

Thompson, M. P., \& Light, L. S. (2011). Examining gender differences in risk factors for suicide attempts made 1 and 7 years later in a nationally representative sample. Journal of Adolescent Health, 48(4), 391-397. https://doi.org/10.1016/j.jadohealth.2010.07.018

Wild, L. G., Flisher, A. J., \& Lombard, C. (2004). Suicidal ideation and attempts in adolescents: Associations with depression and six domains of self-esteem. Journal of Adolescence, 27(6), 611-624. https://doi.org/10.1016/j.adolescence.2004.03.001

Williams, D. R., \& Mulder, J. (2019). BGGM: A R Package for Bayesian Gaussian Graphical Models [Preprint]. PsyArXiv. https://psyarxiv.com/3b5hf/ World Health Organization. (2018). Suicide. https://www.who.int/news-room/factsheets/detail/suicide

Yuodelis-Flores, C., \& Ries, R. K. (2015). Addiction and suicide: A review. American Journal on Addictions, 24, 98-104. https://doi.org/10.1111/ajad.12185 
Table 1. Risk and Protective Factors for Suicide Identified in the Literature

\begin{tabular}{|c|c|}
\hline Factor & Empirical Support \\
\hline \multicolumn{2}{|l|}{ Dynamic risk factor } \\
\hline Substance abuse & $\begin{array}{l}\text { Cherpitel et al. (2004), Conner et al. (2013), Flensborg-Madsen et al. } \\
\text { (2009), Poorolajal et al. (2016), Yuodelis-Flores \& Ries (2015) }\end{array}$ \\
\hline \multirow[t]{3}{*}{ Mental health problems } & Brådvik et al. (2008) - depressive disorders \\
\hline & Kanwar et al. (2013) - anxiety disorders \\
\hline & $\begin{array}{l}\text { Chesney et al. (2014) - substance-use disorder, depression, borderline } \\
\text { personality disorder, bipolar disorder, anxiety disorders, post-traumatic } \\
\text { stress disorder }\end{array}$ \\
\hline Being bullied & Hinduja \& Patchin (2010), Holt et al. (2015), Roeger et al. (2010) \\
\hline Hopelessness & Beck et al. (1985), Kuo et al. (2004), Qiu et al. (2017) \\
\hline Impulsivity & Connor (2011), May \& Klonsky (2015) \\
\hline $\begin{array}{l}\text { Perceived } \\
\text { burdensomeness }\end{array}$ & Bell et al. (2018), Joiner et al. (2002) \\
\hline Stressful life events & Beautrais (2003), Beautrais et al. (1997), Foster (2011) \\
\hline \multicolumn{2}{|l|}{ Protective factor } \\
\hline Social support & Kleiman et al. (2012), Kleiman \& Liu (2013) \\
\hline Self-esteem & Fergusson et al. (2003), Teismann et al. (2019), Wild et al. (2004) \\
\hline Sense of belonging & Hatcher \& Stubbersfield (2013) \\
\hline Stable employment & Coope et al. (2015), Min et al. (2015) \\
\hline Problem solving skills & Abdollahi et al. (2015), Linda et al. (2012), Quiñones et al. (2015) \\
\hline Resilience & Roy et al. (2007), Sher (2019) \\
\hline $\begin{array}{l}\text { Access to mental health } \\
\text { services and a positive } \\
\text { attitude towards them }\end{array}$ & De Hert et al. (2001), Schrijvers et al (2012) \\
\hline
\end{tabular}

Note. This is not a comprehensive list of the risk and protective factors for suicide, or of the empirical evidence supporting these . Risk factor = positively correlated with suicide risk; protective factor $=$ negatively correlated with suicide risk . 
Table 2. Demographic Characteristics of Participants

\begin{tabular}{lcc}
\hline & Frequency & Percentage \\
\hline Gender & 171 & 33.20 \\
Male & 338 & 65.63 \\
Female & 5 & 0.97 \\
Gender diverse & 1 & 0.19 \\
Prefer not to answer & & \\
Country & 198 & 38.45 \\
New Zealand & 32 & 6.21 \\
Australia & 146 & 28.35 \\
United States of America & 138 & 26.80 \\
United Kingdom & & \\
& 153 & 29.71 \\
Age & 164 & 31.84 \\
25 to 34 & 102 & 19.81 \\
35 to 44 & 51 & 9.90 \\
45 to 54 & 36 & 6.99 \\
55 to 64 & 9 & 1.75 \\
65 to 74 & & \\
& & \\
\end{tabular}


Table 3. Descriptive Statistics

\begin{tabular}{lcc}
\hline Variable & $M$ & $S D$ \\
\hline Impulsivity & 2.51 & 0.99 \\
Substance abuse & 1.49 & 0.91 \\
Being bullied & 2.42 & 1.17 \\
Suicidal ideation & 2.54 & 1.42 \\
Resilience & 3.16 & 1.09 \\
Sense of belonging & 3.10 & 1.09 \\
Access to mental health services & 3.69 & 1.01 \\
Positive attitude towards mental health services & 3.91 & 0.98 \\
Social support & 3.72 & 1.12 \\
Stable employment & 3.18 & 1.56 \\
Financial stability & 3.37 & 1.36 \\
Committed relationship & 3.31 & 1.85 \\
Feeling anxious & 3.74 & 1.25 \\
Feeling depressed & 3.32 & 1.34 \\
Feeling hopeless & 3.18 & 1.46 \\
Perceived burdensomeness & 3.08 & 1.48 \\
Problem solving & 3.60 & 1.00 \\
Self-esteem & 2.90 & 1.27 \\
\hline Note. All variabes had a & &
\end{tabular}

Note. All variables had a possible range of 1 to 5 . 
Figure 1. Network structure of risk and protective factors for suicide. Risk and protective factors are shown as nodes, and the relationships between them are shown as edges. Blue edges signify a positive association, whilst red edges signify a negative association. The strength of an association is shown by the thickness of the edge, with a thicker edge representing a stronger association between two nodes.

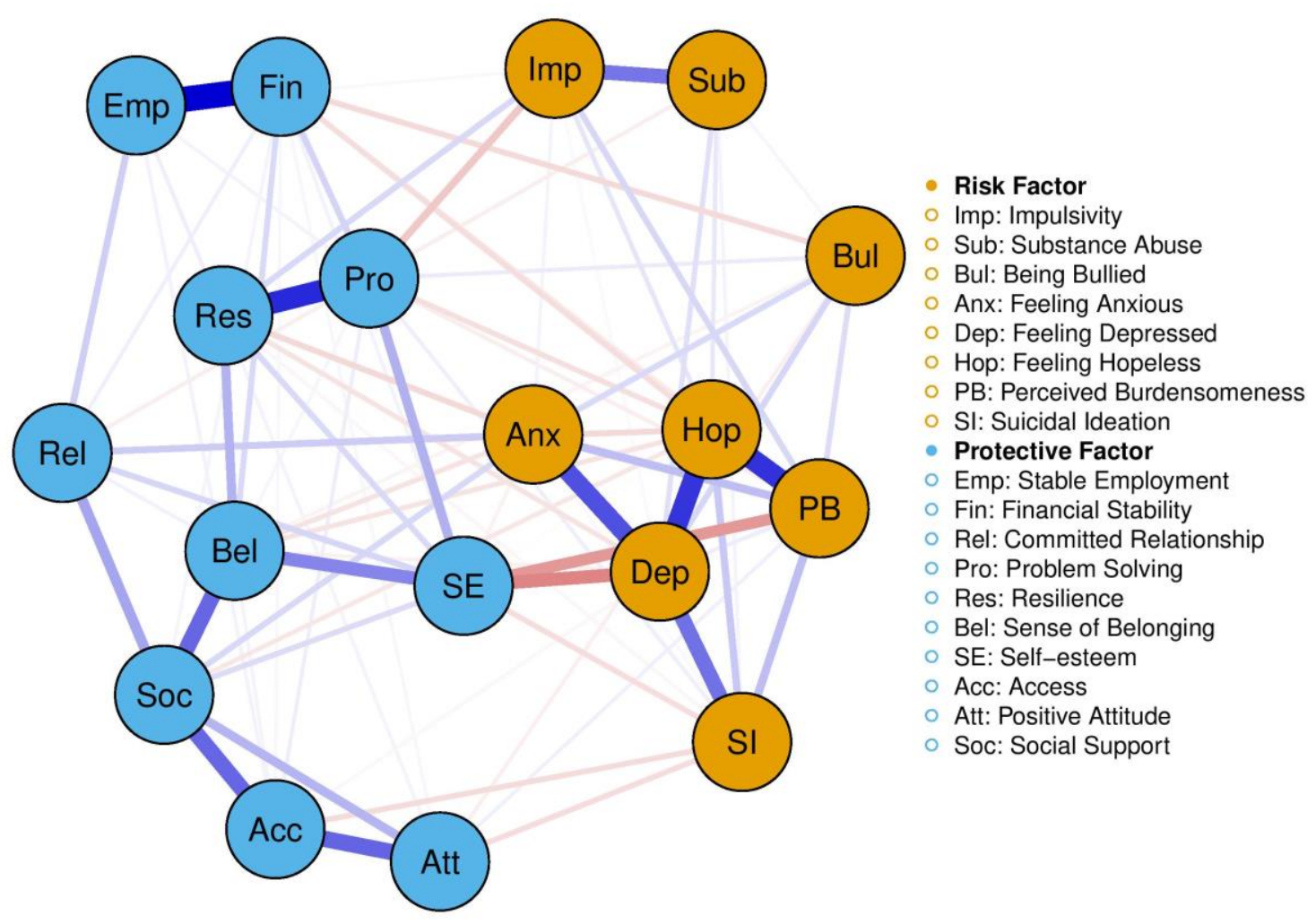


Figure 2. Strength centrality of risk and protective factors for suicide.

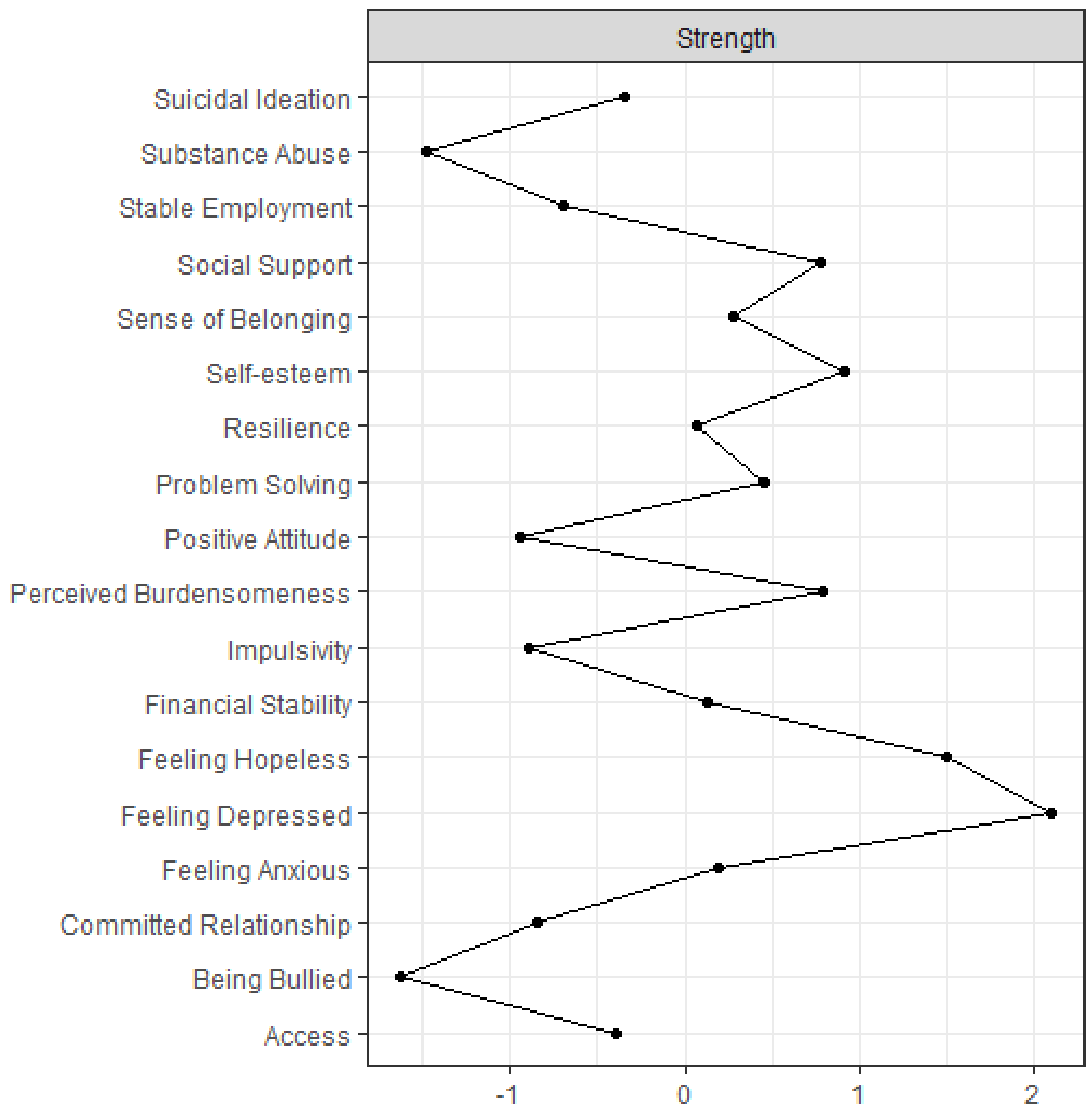

